\title{
A NOTE ON THE ESTIMATE OF GAMMA DISTRIBUTION
}

\author{
DAWEI LU, LIXIN SONG AND Yi WANG
}

Abstract. The lower and upper estimates with explicit coefficients for Gamma distribution are given. Furthermore, using these results, the estimates of spherically symmetric distribution and ellipsoidal distribution are obtained.

Mathematics subject classification (2010): 33B15, 26D15, 60E15. tion.

Keywords and phrases: Gamma distribution, ellipsoidal distribution, spherically symmetric distribu-

\section{REFERENCES}

[1] S.K. BAR-LEV AND B. REISER, A note on maximum conditional likelihood estimation for the gamma distribution, Sankhya, 45, 2 (1983), 300-302.

[2] I.V. BASAWA, A note on estimation of gamma and stable procesess, Biometrika, 67 (1980), 234-236.

[3] N. BATIR, Inequalities for the gamma function, Arch. Math, 91 (2008), 554-563.

[4] Z.W. Birnbaum, An inequality for Mill's ratio, Ann. Math. Statist, 13 (1942), 245-246.

[5] S. Cambanis, S. Huang, G. Simons, On the theory of elliptically contoured distributions, J. Mult. Anal., 10 (1981), 368-385.

[6] P. Diaconis And M.D. Pealman, Bounds for tail probabilities of weighted sums of independent gamma random variables, Lecture Note-Monograph Series, 16 (1990), 147-166.

[7] E. Hashorva ANd J. HÜSLER, On multivariate Gaussian tails, Ann. Inst. Statist. Math, 55, 3 (2003), $507-522$.

[8] J.P. KeAting, R.E. Glaser And N.S. Ketchum, Testing Hypotheses about the sharp parameter of a gamma distribution, Technometrics, 32, 1 (1990), 67-82.

[9] D. Lu AND W.V. Li, A Note on Multivariate Gaussian Estimates, J. Math. Anal. Appl., 354 (2009), 704-707.

[10] G.P. STECK, Lower bounds for the multivariate normal Mills' ratio, Ann. Probab, 7 (1979), 547-551. 